\title{
Lise Gauvin, Cécile Van den Avenne, Véronique Corinus, Ching Selao (dir.), Littératures francophones. Parodies, pastiches, réécritures
}

\section{Emanuela Cacchioli}

\author{
(2) OpenEdition \\ Journals \\ Edizione digitale \\ URL: http://journals.openedition.org/studifrancesi/1636 \\ DOI: $10.4000 /$ studifrancesi. 1636 \\ ISSN: 2421-5856 \\ Editore \\ Rosenberg \& Sellier
}

\section{Edizione cartacea}

Data di pubblicazione: 1 novembre 2014

Paginazione: 640-641

ISSN: 0039-2944

\section{Notizia bibliografica digitale}

Emanuela Cacchioli, «Lise Gauvin, Cécile Van den Avenne, Véronique Corinus, Ching Selao (dir.), Littératures francophones. Parodies, pastiches, réécritures ", Studi Francesi [Online], 174 (LVIII | III) | 2014, online dal 01 novembre 2014, consultato il 18 septembre 2020. URL : http://journals.openedition.org/ studifrancesi/1636; DOI : https://doi.org/10.4000/studifrancesi.1636

Questo documento è stato generato automaticamente il 18 settembre 2020.

\section{cc) (†) $\odot$}

Studi Francesi è distribuita con Licenza Creative Commons Attribuzione - Non commerciale - Non opere derivate 4.0 Internazionale. 


\title{
Lise Gauvin, Cécile Van den Avenne, Véronique Corinus, Ching Selao (dir.), Littératures francophones. Parodies, pastiches, réécritures
}

\author{
Emanuela Cacchioli
}

\section{NOTIZIA}

LISE GAUVIN, CÉCILE VAN DEN AVENNE, VÉRONIQUE CORINUS, CHING SELAO (dir.), Littératures francophones. Parodies, pastiches, réécritures, Lyon, ENS Éditions, 2013, «Signes», pp. 290.

1 L'interesse per le riscritture, le parodie e il pastiche è da sempre centrale nello studio delle letterature francofone e il presente volume è un'ulteriore conferma della vivacità del dibattito e della sua perenne attualità. A introdurre l'opera è Lise GAUvin con il saggio Le palimpseste francophone et la question des modèles (pp. 7-19) che affronta la questione del modello a partire dalla definizione di "palinsesto", formulata da Gérard Genette: in base all'etimologia latina, il palinsesto è una pergamena da cui è stata grattata la prima iscrizione per poterne tracciare un'altra. Il risultato permette di leggere in filigrana la vecchia sotto la nuova. Un'immagine che ci ricorda come il processo di riscrittura permetta di riprendere tracce, echi, impronte di testi precedenti con lo scopo di decostruirli, ricostruirli, criticarli. Il volume ha un triplice scopo. In primis, si propone di indagare i modelli teorici disponibili per descrivere le pratiche di riscrittura e di adattarne il linguaggio alle situazioni concrete. La raccolta di saggi vuole anche essere una sorta di repertorio di testi francesi canonici di riferimento che hanno costituito il punto di partenza per la produzione di nuove opere rese attraverso poetiche narrative peculiari. Una riconfigurazione letteraria che passa per il trasferimento di esperienze culturali e linguistiche e uno sviluppo della dialettica centro/periferia. Il terzo obiettivo corrisponde a un'analisi della dimensione riflessiva 
della scrittura e ad alcune considerazioni sulle condizioni epistemologiche, sociali e storiche alla base della composizione dei testi.

2 La raccolta di saggi ha una struttura tripartita che segue una suddivisione geografica. La prima sezione, dedicata all'Europa e all'America del Nord, si apre con Le pastiche et la parodie. Instruments de mesure des échanges littéraires internationaux (pp. 23-41) di Paul ARON che ripercorre le riscritture dell'opera di Maeterlinck in Belgio e in Francia. Segue lo studio di Réjean BEAUDOIN, Le naturalisme de deux romanciers canadiens-français: Laberge et Ringuet (pp. 43-52) sulla riconfigurazione del naturalismo di Zola nell'opera dei due scrittori quebecchesi. In Généalogie des "Fous de Bassan” d’Anne Hébert (pp. 53-64), Gilles DuPUIS sostiene che i modelli di riferimento per l'autrice canadese sono Faulkner e il ciclo biblico. Nel saggio L'autofiction québécoise. Pastiche et mise en abyme chez Catherine Mavrikakis et Nelly Arcan (pp. 65-75), Mélikah ABDELMOUMEN rintraccia nell'autofinzione quebecchese una matrice più anglosassone che francese. Dominique FISHER sostiene invece che l'opera di Mouawad sia un'eredità dei modelli di Artaud e di Lapage (Détours, nouvelles "polyphonies». Le cas de "Seuls" de Wajdi Mouawad, pp. 77-90). La sezione si chiude con altri due testi sulla letteratura francofona in Canada: si tratta di Une réécriture ambiguë en littérature acadienne. Marguerite Duras et France Daigle (pp. 91-104) di Raoul BOUDREAU e Transtextualité anglo-américaine. "Volskwagen Blues" de Jacques Poulin et “L'Écureuil noir" de Daniel Poliquin (pp. 105-116) di Lucie HоттE.

3 La seconda parte è invece dedicata agli scrittori dei Caraibi e dell'Oceano Indiano. In Littérature-monde, francophonie et ironie: modèles de violence et violence des modèles ( $\mathrm{pp}$. 119-138), Françoise LIONNET riflette sulla nozione di "littérature-monde" proposta dal manifesto del 2007 e sulle riscritture di Paul et Virginie di Bernardin de Saint-Pierre. Seguono due articoli sulla favola. Il primo, che ne analizza il valore ideologico della riscrittura, è di Michel BeniAmino (Réflexions sur l'imitation. L'exemple des fables créoles, pp. 139-153). Nel secondo (Charles Perrault et Léon-Gontran Damas. Une relation parodique, pp. 155-162), Carla FrATTA si sofferma sulla ripresa delle favole di Charles Perrault. Nel saggio La nouvelle régionaliste créole et l'oscillation des modèles (pp. 165-174), Véronique CORINUS ci fornisce un esempio di estrema valorizzazione dell'ipotesto metropolitano. Le nozioni di "créolité" et di "créolisation" e il dibattito teorico che si è sviluppato attorno ad esse è l'argomento centrale di Édouard Glissant et Patrick Chamoiseau. Construire un paradigme antillais (pp. 175-188) di Dominique C HANCÉ. Ching SELAO analizza, invece, le forme di "marronage" presenti nell'opera di Maryse Condé in Le double palimpseste de Maryse Condé. "Moi, Tituba sorcière... Noire de Salem" (pp. 189-202). Chiude la sezione Figures d'écrivains caribéens. Autofictions d'auteurs haïtiens (pp. 203-214) in cui Yolaine PARISOT riflette sul modello caraibico e sull'articolazione del discorso globale-locale.

La terza parte, dedicata all'Africa, si apre con Subversion et réécriture du modèle romanesque dans "Nedjma" de Kateb Yacine (pp. 217-228) nel quale Charles BonN analizza la sovversione formale che deriva dall'uso della parodia e del pastiche. In La supercherie du "Regard du roi" de Camara Laye. À quoi sert la critique? (pp. 229-240), Daniel Delas si chiede come affrontare le opere scritte da un autore e firmate da un altro. Isaac BAzIÉ, con il saggio Réécritures, stratégies de lecture et seuil de tolérance dans "Le Devoir de violence" (pp. 241-253) esamina l'approccio del lettore di fronte all'evoluzione dei testi. L'articolo di Auguste Léopold MBONDÉ MOUANGUÉ, Le griot comme modèle énonciatif dans "Peuls" de Monénembo (pp. 255-261), si propone, invece, di individuare le strategie narrative che 
ricordano la performance del "griot" e permettono di rintracciare la memoria collettiva. Chiude il volume il saggio Reprise et détournement d'un stéréotype linguistique. Les enjeux coloniaux et postcoloniaux de l'usage du «petit-nègre» dans la littérature africaine (pp. 263-275), in cui Cécile VAN DEN AVENNE considera le modalità di rappresentazione del francese popolare africano da parte di alcuni romanzieri.

5 Il volume vuole essere una riflessione sulla pratica della riscrittura, non come imitazione servile di un modello europeo, bensì come processo di assimilazione e di trasformazione in continuo divenire. Per quanto frammentaria e non esaustiva, la raccolta di saggi si presenta come un dialogo transtestuale e ci offre un'idea di letteratura come passaggio e trasferimento da un testo ad un altro. 